\title{
Prognostic significance of unintentional body weight loss in colon cancer patients
}

\author{
YI-HUNG KUO ${ }^{1,2}$, CHUNG-SHENG SHI ${ }^{2}$, CHENG YI HUANG ${ }^{1}$, YUN-CHING HUANG ${ }^{2}$ and CHIH-CHIEN CHIN ${ }^{1,2}$ \\ ${ }^{1}$ Division of Colon and Rectal Surgery, Department of Surgery, Chang Gung Memorial Hospital, Puzeh, Chiayi 61363; \\ ${ }^{2}$ Graduate Institute of Clinical Medical Science, College of Medicine, Chang Gung University, Taoyuan 33302, Taiwan, R.O.C.
}

Received September 28, 2017; Accepted February 5, 2018

DOI: $10.3892 /$ mco.2018.1582

\begin{abstract}
The aim of the present study was to investigate whether unintentional body weight loss (BWL) provides additional clinical information in terms of tumor progression and prognosis in non-metastatic colon cancer. In the present study, a total of 2,406 consecutive colon cancer patients without metastasis were retrospectively enrolled. Unintentional BWL was defined as loss of $>5 \%$ of body weight within the last 6-12 months, or defined subjectively upon fulfillment of at least two of the following: Evidence of change in clothing size and corroboration of the reported weight loss by family or friend. This category was recorded as present ('with') or absent ('without'). Logistic regression analysis was performed to determine the correlation between BWL and the tumor characteristics and post-operative outcomes of patients with colon cancer. The Cox regression model was used to determine the association of BWL with long-term survival of colon cancer patients. A significant association between BWL and tumor location [right vs. left: Odds ratio $(\mathrm{OR})=1.62 ; \mathrm{P}<0.001$ ], tumor size ( $\geq 5$ vs. $<5 \mathrm{~cm}$ : $\mathrm{OR}=2.17 ; \mathrm{P}<0.001$ ), and tumor stage based on the tumor-nodes-metastasis system (T3-T4 vs. T1-T2: $\mathrm{OR}=2.02 ; \mathrm{P}<0.001)$. Post-operative morbidity and mortality were not significantly influenced by BWL. Multivariate analysis revealed that BWL was significantly associated with overall survival [with vs. without BWL: Hazard ratio $(\mathrm{HR})=1.178 ; \mathrm{P}=0.036$ ] and relapse-free survival (with vs. without BWL: $\mathrm{HR}=1.332 ; \mathrm{P}=0.003$ ). In conclusion, BWL in patients with colon cancer is not just a symptom, but it is also correlated with tumor location, size and depth, and is a prognostic factor for poor outcomes including overall survival and tumor relapse.
\end{abstract}

Correspondence to: Dr Chih-Chien Chin, Division of Colon and Rectal Surgery, Department of Surgery, Chang Gung Memorial Hospital, Chiayi Branch, 6 West Chia-Pu Road, Puzeh, Chiayi 61363, Taiwan, R.O.C.

E-mail: ccchin3477@gmail.com

Key words: unintentional, body weight loss, colon cancer, prognosis, survival

\section{Introduction}

The incidence rates of colon cancer have been increasing worldwide. The diagnosis of colon cancer is based on the patients' symptoms or the results of a health examination. The clinical presentations of colon cancer, which are attributed to tumor growth, include abdominal pain, change in bowel habits, bleeding, mucus passage, unintentional body weight loss (BWL), presence of an abdominal mass and more severe presentations, including obstruction and peritonitis. The BWL is a common symptom of malignant diseases, particularly malignancies of the digestive system $(1,2)$. In colon cancer patients, unintentional BWL in the absence of other signs or symptoms is associated with poor prognosis (3). Unintentional BWL in colon cancer patients also indicates an advanced disease stage $(3,4)$.

However, little is known regarding the association between BWL at presentation and the characteristics of non-metastatic colon tumors and the influence of unintentional BWL on the prognostic outcomes of colon cancer patients. The aim of the present study was to determine whether unintentional BWL may provide additional information with regard to tumor progression and patient prognosis, apart from the presence of colon cancer.

\section{Patients and methods}

Patients. In the present study, a total of 2,406 patients with colon cancer who underwent elective and potentially curative surgery at Chang Gung Memorial Hospital (Puzeh, China) between January 1995 and December 2004 were enrolled. The appropriate approval from the Institutional Review Board of Chang Gung Memorial Hospital (Puzeh, China) was obtained (no. 104-6053B). As the present study was retrospective, patients were exempt from providing informed consent. The patients completed a pre-operative questionnaire on their symptoms as part of their admission. Patients with metastasis [stage IV colon cancer of the tumor-nodes-metastasis (TNM) staging system], previous colon surgery, or synchronous right and left colon cancers were excluded from the present study.

The patients were classified according to their age into 3 groups: $<50$ years (young), 50-75 years (middle-age) and $>75$ years (old). Unintentional BWL was defined numerically as weight loss of at least $5 \mathrm{~kg}$ (or $>5 \%$ of body weight) 
within the recent 6-12 months (5), or defined subjectively based on the following: Evidence of change in clothing size and corroboration of the reported weight loss by a family member or friend (6). BWL data were recorded for patients who were able to provide it. Hypoalbuminemia was defined as the condition in which serum albumin levels were $<3.5 \mathrm{~g} / 1$. Carcinoembryonic antigen (CEA) levels $>5 \mathrm{ng} / \mathrm{ml}$ were considered abnormal. Hemoglobin levels $<10 \mathrm{~g} / \mathrm{dl}$ were considered to indicate 'obvious anemia'. Tumor stages were determined on the basis of the American Joint Committee on Cancer TNM staging system (6th edition). Tumor location was categorized as in the right colon (from the cecum to transverse colon) or left colon (from the splenic flexure to the sigmoid colon). Tumor morphology was classified as polypoid (including flat and polypoid tumors) and non-polypoid (including ulcerative and infiltrative tumors). The tumors were classified into 2 groups: $<5 \mathrm{~cm}$ (in length and width) and $\geq 5 \mathrm{~cm}$ (either length or width).

The patients were divided into 2 groups based on the presence or absence of BWL: With BWL or without BWL. Patients in whom body weight loss data were available were further divided into different groups based on the extent of body weight loss. All patients underwent standard oncological resection of the colonic tumors and received routine post-operative care.

Post-operative morbidities were defined as complications occurring within 30 days of the primary surgery, and post-operative mortality was defined as death within 30 days of the primary surgery. Overall survival (OS), calculated after considering death from any cause, and relapse-free survival (RFS), calculated after considering any relapses from the index cancer, were the only events considered for survival analyses. Relapses of cancer were confirmed histologically or radiographically.

Statistical analysis. Quantitative data were compared using Pearson's chi-squared and Fisher's exact tests. For multivariate analysis, logistic regression was used to determine any confounding factors of BWL, and the Hosmer-Lemeshow test was used to test the goodness-of-fit of this logistic regression model. The OS and RFS were calculated using the Kaplan-Meier method. Survival curves of the different groups were plotted using the Kaplan-Meier method and were compared using the log-rank test. In order to compensate for the confounding factors, the Cox regression model was used for multivariate analysis. All P-values were two-tailed and $\mathrm{P}<0.05$ was considered to indicate a statistically significant difference. All statistical analyses were performed using SPSS Statistics software version 17.0.1 (SPSS, Inc., Chicago, IL, USA).

\section{Results}

Association of BWL with clinicopathological characteristics. The clinicopathological characteristics of colon cancer patients with unintentional BWL are presented in Table I. Within the cohort, the percentage of colon cancer patients with BWL but without metastatic disease was $38.1 \%$. No significant differences in the percentage of patients with BWL with regard to age $(\mathrm{P}=0.409)$, sex $(\mathrm{P}=0.245), \mathrm{N}$-stage of the TNM system $(\mathrm{P}=0.178)$ and histological type $(\mathrm{P}=0.144)$ were noted. Non-polypoid tumors $(\mathrm{P}<0.001)$, right colon tumors
( $\mathrm{P}<0.001$ ), large tumors (tumor size $>5 \mathrm{~cm} ; \mathrm{P}<0.001$ ), poorly differentiated tumors $(\mathrm{P}<0.001)$, stage II tumors $(\mathrm{P}<0.001)$ and advanced $\mathrm{T}$-stage tumors $(\mathrm{P}<0.001)$ were more likely to be associated with BWL. As these significant factors (TNM stage, tumor morphology, tumor location, tumor size, T-stage of TNM system and histologic grade) associated with BWL are also linked with each other, forward stepwise logistic regression was performed to determine which of these factors were independently associated with BWL. As presented in Table II, the significant factors were tumor location, [right vs. left: odds ratio $(\mathrm{OR})=1.62 ; 95 \%$ confidence interval $(\mathrm{CI})$, 1.36-1.94; $\mathrm{P}<0.001$ ], tumor size ( $\geq 5$ vs. $<5 \mathrm{~cm}$ : $\mathrm{OR}=2.17$; 95\% CI, 1.81-2.59; $\mathrm{P}<0.001)$ and $\mathrm{T}$-stage of TNM system (T3-T4 vs. T1-T2: OR=2.02; 95\% CI, 1.51-2.70; $\mathrm{P}<0.001$ ). The goodness-of-fit of this logistic regression model was good, and the P-value obtained was 0.994 .

The association between pre-operative laboratory data of BWL and patients (CEA, albumin and hemoglobin levels) and post-operative morbidity and mortality are presented in Table III. Compared to patients without BWL, those with BWL were more likely to have hypoalbuminemia (25.4 vs. $14.5 \%$; $\mathrm{P}<0.001)$, obvious anemia (36.7 vs. $22.9 \%$; $\mathrm{P}<0.001)$ and abnormal CEA levels (39.5 vs. $34.9 \%$; $\mathrm{P}=0.028$ ).

No significant differences in post-operative morbidity (12.7 vs. $11.1 \% ; \mathrm{P}=0.238)$ and mortality (1.4 vs. $0.8 \% ; \mathrm{P}=0.149)$ were noted between patients with and without BWL. The cut-off value for BWL was assessed to determine whether the extent of BWL would increase the risk of mortality and morbidity. However, only when patients presented with BWL of $\geq 6 \mathrm{~kg}$, a slightly higher morbidity rate (14.1\%) compared with patients with BWL of $<6 \mathrm{~kg}(10.9 \%)$ or without BWL (11.1\%) was identified, but the difference was not significant $(\mathrm{P}=0.053)$. There were no significant differences in post-operative mortality rates between these three groups.

Survival analysis. Within the cohort, the percentage of stage III colon cancer patients receiving adjuvant chemotherapy post-operatively was not significantly different between the groups with and without BWL (71.5 vs. $73.0 \%$; $\mathrm{P}=0.627)$. The 5 -year OS and RFS rates in the present study were 74.0 and $78.2 \%$, respectively. When stratified according to BWL, the 5-year OS rates of patients without and with BWL were 76.5 and $71.1 \%$, respectively $(\mathrm{P}=0.0308)$, and the 5 -year RFS rates were 80.1 and $75.5 \%$, respectively $(\mathrm{P}=0.0033)$. Compared to patients without BWL, those with BWL had significantly poorer OS and RFS rates (Fig. 1). In addition, the cut-off value to define $\mathrm{BWL}$ was varied from 3 to $10 \mathrm{~kg}$ to determine whether a greater extent of BWL is associated with poorer survival. However, there was no significant difference in OS and RFS rates between the two stratified groups of patients with BWL.

To elucidate the influence of BWL on patient survival, a multivariate analysis was performed using the Cox regression method. Predictive factors for this regression model included BWL, TNM stage, age, sex, CEA levels and morbidity, as well as tumor location, morphology, size, histological type and histological grade; the results of this analysis are presented in Table IV (OS and RFS). Significant predictors regarding the OS rate were TNM stage [stage II vs. I: hazard ratio $(\mathrm{HR})=1.160$; 95\% CI, 0.837-1.607, $\mathrm{P}=0.373$; stage III vs. I: $\mathrm{HR}=1.971$; 
Table I. Clinicopathological characteristics of patients with or without BWL.

\begin{tabular}{|c|c|c|c|}
\hline Parameter & $\begin{array}{l}\text { No BWL } \\
(n=1,490)\end{array}$ & $\begin{array}{c}\text { BWL } \\
(n=916)\end{array}$ & P-value \\
\hline Age (years) & & & 0.409 \\
\hline$<50$ & $280(18.8)$ & $189(20.6)$ & \\
\hline $50-75$ & $953(64.0)$ & $583(63.6)$ & \\
\hline$>75$ & $257(17.2)$ & $144(15.7)$ & \\
\hline Sex & & & 0.245 \\
\hline Female & $707(47.4)$ & 457 (49.9) & \\
\hline Male & $783(52.6)$ & $459(50.1)$ & \\
\hline Tumor morphology & & & $<0.001$ \\
\hline Polypoid & $414(27.8)$ & $196(21.4)$ & \\
\hline Non-polypoid & $1,076(72.2)$ & $720(78.6)$ & \\
\hline Tumor location & & & $<0.001$ \\
\hline Right & 485 (32.6) & $447(48.8)$ & \\
\hline Left & $1,005(67.4)$ & $469(51.2)$ & \\
\hline Tumor size (cm) & & & $<0.001$ \\
\hline$<5$ & $886(59.5)$ & $325(35.5)$ & \\
\hline$\geq 5$ & $6.4(40.5)$ & $591(64.5)$ & \\
\hline TNM stage & & & $<0.001$ \\
\hline I & $234(15.7)$ & $56(6.1)$ & \\
\hline II & $664(44.6)$ & $509(55.6)$ & \\
\hline III & $592(39.7)$ & $351(38.3)$ & \\
\hline TNM T-stage & & & $<0.001$ \\
\hline T1-T2 & $281(18.9)$ & $68(7.4)$ & \\
\hline T3-T4 & $1,209(81.1)$ & $848(92.6)$ & \\
\hline TNM N-stage & & & 0.178 \\
\hline N0 & $898(60.3)$ & $565(61.7)$ & \\
\hline N1 & $394(26.4)$ & $214(23.4)$ & \\
\hline $\mathrm{N} 2$ & $198(13.3)$ & $137(15.0)$ & \\
\hline Histologic type & & & 0.144 \\
\hline Adenocarcinoma & $1,364(91.5)$ & $817(89.2)$ & \\
\hline Signet ring cell & $8(0.5)$ & $5(0.5)$ & \\
\hline Mucinous & $118(7.9)$ & $94(10.3)$ & \\
\hline Histologic grade/ & & & $<0.001$ \\
\hline \multicolumn{4}{|l|}{ differentiation } \\
\hline Well & $325(21.8)$ & $156(17.0)$ & \\
\hline Moderate & $1,102(74.0)$ & $689(75.2)$ & \\
\hline Poor & $63(4.2)$ & $71(7.8)$ & \\
\hline
\end{tabular}

Values are expressed as n (\%). TNM, tumor-nodes-metastasis; BWL, body weight loss.

95\% CI, 1.428-2.721, $\mathrm{P}<0.001)$, age (middle age vs. young: $\mathrm{HR}=1.471 ; 95 \% \mathrm{CI}, 1.163-1.860, \mathrm{P}=0.001$; old vs. young: $\mathrm{HR}=3.264$; 95\% CI, 2.524-4.222, $\mathrm{P}<0.001$ ), sex (male vs. female: $\mathrm{HR}=1.221$; 95\% CI, 1.053-1.416, $\mathrm{P}=0.008$ ), $\mathrm{BWL}$ (with vs. without BWL: $\mathrm{HR}=1.178$; 95\% CI, 1.011-1.372, $\mathrm{P}=0.036$ ), CEA level ( $\geq 5$ vs. $<5$ ng/ml: HR=1.619; 95\% CI, 1.394-1.881, $\mathrm{P}<0.001$ ), albumin level (<35 vs. $\geq 35$ g/l: HR=1.752; 95\% CI, $1.468-2.093, \mathrm{P}<0.001$ ) and post-operative morbidity (with vs.
Table II. Significant variables associated with the presence of body weight loss by forward stepwise logistic regression.

\begin{tabular}{lcc}
\hline Variable & P-value & OR (95\% CI) \\
\hline $\begin{array}{l}\text { Tumor location } \\
\text { (right vs. left) }\end{array}$ & $<0.001$ & $1.62(1.36-1.94)$ \\
$\begin{array}{l}\text { Tumor size } \\
(\geq 5 \text { vs. }<5 \mathrm{~cm})\end{array}$ & $<0.001$ & $2.17(1.81-2.59)$ \\
$\begin{array}{l}\text { T-stage of TNM } \\
(\mathrm{T} 3-\mathrm{T} 4 \text { vs. T1-T2) }\end{array}$ & $<0.001$ & $2.02(1.51-2.70)$ \\
\hline
\end{tabular}

Variables in forward stepwise logistic regression include tumor morphology, tumor location, tumor size, T stage of TNM system and histological grade. OR, odds ratio; CI, confidence interval; TNM, tumor-nodes-metastasis.

without: $\mathrm{HR}=1.484 ; 95 \%$ CI, 1.216-1.812, $\mathrm{P}<0.001)$. However, other factors, including hemoglobin level, tumor location, tumor morphology, tumor size, histological type and histological grade, had no significant influence on OS. Significant predictors of RFS were TNM stage (stage II vs. I: HR=1.817; $\mathrm{P}=0.031$; stage III vs. I: $\mathrm{HR}=4.177 ; \mathrm{P}<0.001$ ), $\mathrm{BWL}$ (with BWL vs. without BWL: $\mathrm{HR}=1.332 ; \mathrm{P}=0.003)$, CEA level ( $\geq 5$ vs. $<5 \mathrm{ng} / \mathrm{ml}$ : HR=1.954; $\mathrm{P}<0.001$ ), tumor morphology (non-polypoid vs. polypoid: $\mathrm{HR}=1.697$; $\mathrm{P}<0.001$ ) and histological type (signet ring cell vs. adenocarcinoma: $\mathrm{HR}=3.091$; $\mathrm{P}=0.003$; mucinous vs. adenocarcinoma: $\mathrm{HR}=1.076 ; \mathrm{P}=0.663$, not significant).

Taken together, the survival analysis indicated that the BWL was a significant predicator of poor OS and RFS.

\section{Discussion}

The incidence rate of colon cancer has been increasing worldwide and is also a leading cause of cancer-associated mortality (7). The time taken for the diagnosis of colon cancer varies and depends on the economic and medical resources available. In developed countries, colon cancers are diagnosed in numerous asymptomatic patients who undergo screening or who undergo examination due to other clinical problems, including anemia. However, in countries where regular health surveillance is not common, colon cancers are diagnosed only when patients present with associated symptoms. The most common symptoms of colon cancer are abdominal pain, change in bowel habits, rectal bleeding and occult blood in the stool (8). In addition, BWL is a common symptom of colon cancer $(3,4)$. In the present study, BWL was present in $38.1 \%$ of the colon cancer patients without metastasis and $50.6 \%$ of the patients with metastasis.

The predominant etiologies leading to unintentional BWL are digestive organic disorders, including non-malignant and malignant disease (6). In the present study, the prevalence of BWL in colon cancer patients was not significantly associated with patient age, sex, N-stage of the TNM system and histological type, but significantly associated with the tumor morphology, location, size, depth and differentiation. According to the present analyses, BWL is more likely to occur 
Table III. Correlation between body weight loss and patient's pre-operative laboratory data and post-operative morbidity and mortality.

\begin{tabular}{|c|c|c|c|c|}
\hline Parameter & Total, n (\%) & No BWL, n (\%) & BWL, n (\%) & P-value \\
\hline \multicolumn{5}{|l|}{ Albumin } \\
\hline$<35 \mathrm{~g} / 1$ & $450(18.7)$ & $216(14.5)$ & $234(25.4)$ & $<0.001$ \\
\hline \multicolumn{5}{|c|}{ Hemoglobin } \\
\hline$<10 \mathrm{~g} / \mathrm{dl}$ & $676(28.1)$ & $340(22.9)$ & $336(36.7)$ & $<0.001$ \\
\hline \multicolumn{5}{|l|}{ CEA } \\
\hline$\geq 5 \mathrm{ng} / \mathrm{ml}$ & $883(36.7)$ & $520(34.9)$ & $363(39.5)$ & 0.028 \\
\hline \multicolumn{5}{|c|}{ Post-surgical morbiditya } \\
\hline Yes & $280(11.6)$ & $163(10.9)$ & $117(12.7)$ & 0.238 \\
\hline \multicolumn{5}{|c|}{ Post-surgical mortality } \\
\hline Yes & $26(1.1)$ & $13(0.8)$ & $13(1.4)$ & 0.149 \\
\hline
\end{tabular}

${ }^{\mathrm{a} C}$ Complications occurring within 30 days of the primary surgery. ${ }^{\mathrm{b}}$ Mortality within 30 days of the primary surgery. CEA, carcinoembryonic antigen; BWL, body weight loss.
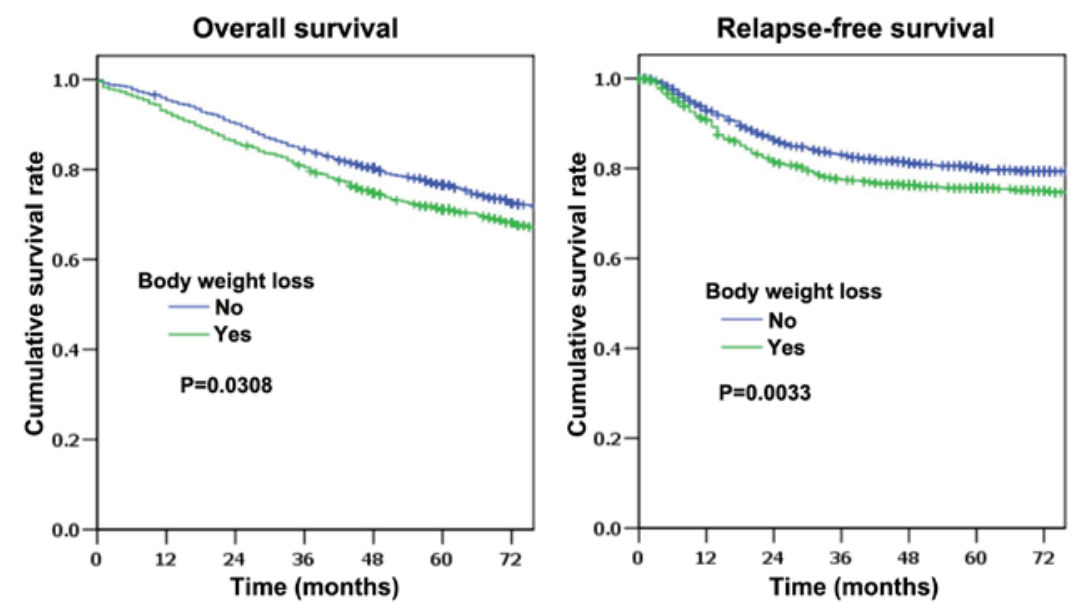

Figure 1. Kaplan-Meier overall survival curves and relapse-free survival curves of non-metastatic colon cancer patients stratified by body weight loss (with or without).

in colon cancer patients with non-polypoid than in those with polypoid tumors, in patients with right colon tumors than in those with left colon tumors, in patients with larger tumors than in those with smaller tumors, in patients with locally advanced tumors (T3-T4 vs. T1-T2 stage), and in patients with poorly differentiated than in those with well to moderately differentiated tumors. The results of the multivariate logistic regression analysis indicated that BWL in colon cancer is significantly associated with the location, size and depth of tumors. Previous studies on the association between BWL and the cancer location are controversial; Kent et al (9) have reported that weight loss was not associated with cancer location, while Bloem et al (10) have reported that BWL is a common symptom in patients with right-sided cancers. The results of the present study are in agreement with those of Bloem et al (10), who indicated that BWL is associated with the cancer location and is common in right-sided cancers.

In the present study, BWL in colon cancer patients was indicated to be associated with advanced disease stage and poor prognosis. During the same study period, a total of
731 patients presented with metastatic disease at our institution. Although these patients were excluded from the present study, a comparative analysis indicated that patients with BWL had a higher risk of having metastatic disease than those without BWL (29.2 vs. $20.8 \%$ respectively). However, BWL was more commonly observed in stage II than in stage III patients. BWL was identified to be correlated with tumor depth, but not with the nodal status; all stage-II cancers were locally advanced (T3-T4 stage) but certain stage III cancers were not (T1-T2 tumors). This result suggested that BWL in patients with non-metastatic colon cancer is not attributed to the progression of the tumor but to tumor depth.

Little is known about the effects of pre-operative BWL in patients undergoing colon surgery. In a French prospective multicenter study, Alves et al (11) have reported that BWL of $>10 \%$ in $<6$ months significantly increased post-operative mortality after resection in patients with colon cancer or diverticulitis. Higgens et al (12) have reported that in patients undergoing elective resection for inflammatory bowel disease, pre-operative weight loss did not adversely affect the post-operative outcome. 
Table IV. Results of a Cox proportional hazard model analysis to identify the significant variables of overall survival and relapse-free survival.

\begin{tabular}{|c|c|c|c|c|}
\hline \multirow[b]{2}{*}{ Variable } & \multicolumn{2}{|c|}{ Overall survival analysis } & \multicolumn{2}{|c|}{ Relapse-free survival analysis } \\
\hline & P-value & $\mathrm{HR}(95 \% \mathrm{CI})$ & P-value & $\mathrm{HR}(95 \% \mathrm{CI})$ \\
\hline TNM stage & $<0.001$ & & $<0.001$ & \\
\hline II vs. I & 0.373 & $1.160(0.837-1.607)$ & 0.031 & $1.817(1.057-3.123)$ \\
\hline III vs. I & $<0.001$ & $1.971(1.428-2.721)$ & $<0.001$ & $4.177(2.451-7.116)$ \\
\hline Age (years) & $<0.001$ & & 0.412 & \\
\hline $50-75$ vs. $<50$ & 0.001 & $1.471(1.163-1.860)$ & 0.188 & $1.179(0.922-1.508)$ \\
\hline$>75$ vs. $<50$ & $<0.001$ & $3.264(2.524-4.222)$ & 0.498 & $1.115(0.815-1.525)$ \\
\hline Sex (male vs. female) & 0.008 & $1.221(1.053-1.416)$ & 0.499 & $1.064(0.889-1.275)$ \\
\hline BWL (with vs. without) & 0.036 & $1.178(1.011-1.372)$ & 0.003 & $1.332(1.105-1.606)$ \\
\hline $\mathrm{CEA}(\geq 5 \mathrm{vs} .<5 \mathrm{ng} / \mathrm{ml})$ & $<0.001$ & $1.619(1.394-1.881)$ & $<0.001$ & $1.954(1.628-2.345)$ \\
\hline Hemoglobin $(<10 \mathrm{vs} . \geq 10 \mathrm{~g} / \mathrm{dl})$ & 0.296 & $1.097(0.922-1.304)$ & 0.807 & $1.027(0.828-1.274)$ \\
\hline Albumin $(<35 \mathrm{vs} . \geq 35 \mathrm{~g} / \mathrm{l})$ & $<0.001$ & $1.752(1.468-2.093)$ & 0.081 & $1.237(0.974-1.572)$ \\
\hline Morbidity (with vs. without) & $<0.001$ & $1.484(1.216-1.812)$ & 0.838 & $0.970(0.723-1.300)$ \\
\hline Tumor location (left vs. right) & 0.446 & $1.066(0.904-1.257)$ & 0.655 & $0.955(0.782-1.167)$ \\
\hline $\begin{array}{l}\text { Tumor morphology } \\
\text { (non-polypoid vs. polypoid) }\end{array}$ & 0.128 & $1.164(0.957-1.417)$ & $<0.001$ & $1.697(1.292-2.229)$ \\
\hline Tumor size ( $\geq 5$ vs. $<5 \mathrm{~cm}$ ) & 0.157 & $0.890(0.757-1.046)$ & 0.107 & $0.851(0.700-1.035)$ \\
\hline Histologic type & 0.207 & & 0.013 & \\
\hline Signet ring cell vs. adenocarcinoma & 0.125 & $1.771(0.853-3.678)$ & 0.003 & $3.091(1.455-6.565)$ \\
\hline Mucinous vs. adenocarcinoma & 0.353 & $1.137(0.867-1.491)$ & 0.663 & $1.076(0.773-1.500)$ \\
\hline Histologic grade/differentiation & 0.260 & & 0.847 & \\
\hline Moderate vs. well & 0.444 & $1.084(0.882-1.333)$ & 0.781 & $1.038(0.797-1.352)$ \\
\hline Poor vs. well & 0.101 & $1.354(0.943-1.945)$ & 0.565 & $1.143(0.726-1.798)$ \\
\hline
\end{tabular}

HR, hazard ratio; CI, confidence interval; CEA, carcinoembryonic antigen; BWL, body weight loss; TNM, tumor-nodes-metastasis.

Piessen et al (13) have reported that weight loss is not an independent risk factor for morbidity in colon cancer patients who underwent left hemicolectomy. In the present study, the operative morbidity and mortality rates were not significantly different between colon cancer patients with and without BWL.

Whether pre-operative BWL influences long-term survival and relapse in colon cancer patients is not well studied. Burdy et al (14) have reported that in patients with T3-T4 node-negative colon cancer patients, weight loss $(>5 \mathrm{~kg})$ is not a significant factor for tumor recurrence according to multivariate analysis; however, it is a significant factor according to univariate analysis. Diculescu et al (15) have reported that the weight loss index is an independent prognostic factor for colorectal cancer progression. Andreyev et al (16) have reported that weight loss at presentation was an independent predictive factor of poor prognosis in colon cancer patients who received adjuvant chemotherapy; however, they proposed that the poor outcome may be due to these patients receiving significantly lower doses of chemotherapy. In the present study, BWL was determined to be an independent risk factor for poor prognosis not only regarding OS but also RFS. In other words, compared to patients without BWL, patients with BWL at presentation exhibited poorer long-term survival and higher tumor relapse rates. Barber et al (17) have reported that BWL in cancer patients may be attributed to anorexia, hypermetabolism and substrate metabolism. They have also reported that cytokines, hormones and tumor-specific products may be the mediators of abnormal metabolism. Certain mediators, including tumor necrosis factor $(18,19)$ and interleukin-6 $(20)$, have been correlated with cancer metastasis. These mechanisms and mediators may partly explain the correlation between BWL and a relapse of cancer. Further study is warranted to investigate whether reducing BWL (by blocking the mechanisms or mediators) in cancer patients may decrease the risk of cancer metastasis.

The present study has certain limitations. First, it was a retrospective study at a single institute. Furthermore, the definition of unintentional BWL included numerical documentation and subjective determination of change in clothing size or looks; therefore, these data on BWL may not be reliable. While subjective rating of BWL may be inaccurate, Re and Rule (21) demonstrated that humans are able to identify weight changes in another person based on their face when women or men of average height gain or lose $3.6-4.0 \mathrm{~kg}$. The average worldwide body weight of humans is $62.0 \mathrm{~kg}$ (22) and loss of body weight of 3.6 and $4.0 \mathrm{~kg}$ accounts for 5.8 and $6.4 \%$ of the average body weight. Therefore, subjective ratings of changes in clothing size or looks by patients' relatives may be reasonable for identifying BWL.

Apart from the clothing size, additional scientific data may be required to confirm the conclusions of the present study. Additional factors, e.g. the presence of diabetes or stress, may 
also have contributed to the weight loss, which may be investigated in future studies. In the present retrospective study, the possible influence of diabetes on a patient's body weight was analyzed. Patients with diabetes respectively accounted for $10.9 \%$ of the BWL group and $13.2 \%$ of the non-BWL group $(\mathrm{P}=0.097$; data not shown). However, no unified numerical scale was used to exactly determine BWL, as the exact amount of BWL was not recorded in all patients. Due to these limitations, the association between the index of BWL and the characteristics of colon cancer patients was not accurately established.

In conclusion, unintentional BWL in colon cancer patients is not just a symptom but is also associated with tumor location, size and depth. It is also a prognostic factor for poor outcomes, including OS and tumor relapse.

\section{Acknowledgements}

The authors of the present study would like to thank Professor Jeng-Yi Wang, Professor Chung-Rong Changchien, Professor Reiping Tang, Professor Jinn-Shiun Chen, Professor Jy-Ming Chiang, Dr Chien-Yuh Yeh and Dr Wen-Shih Huang (all Division of Colon and Rectal Surgery, Department of Surgery, Chang Gung Memorial Hospital, New Taipei, Taiwan) for setting up and providing the patient's database.

\section{Funding}

No funding was received.

\section{Availability of data and materials}

The datasets used and/or analyzed during the current study are available from the corresponding author on reasonable request.

\section{Authors' contributions}

YHK and CCC designed the study, performed the majority of the experiments and wrote the manuscript. YCH and CSS analyzed the patient's data. CYH helped to collect patient's data.

\section{Ethics approval and consent to participate}

Appropriate ethical approval was obtained from the Institutional Review Board of Chang Gung Memorial Hospital (Puzeh, China; no. 104-6053B). Patient consent was not required for the present study as it was conducted retrospectively.

\section{Consent for publication}

Not applicable.

\section{Competing interests}

The authors confirm that they have no competing interests.

\section{References}

1. Bozzetti F; SCRINIO Working Group: Screening the nutritional status in oncology: A preliminary report on 1,000 outpatients Support Care Cancer 17: 279-284, 2009.
2. Nourissat A, Mille D, Delaroche G, Jacquin JP, Vergnon JM, Fournel P, Seffert P, Porcheron J, Michaud P, Merrouche Y and Chauvin F: Estimation of the risk for nutritional state degradation in patients with cancer: Development of a screening tool based on results from a cross-sectional survey. Ann Oncol 18: 1882-1886, 2007.

3. Corman ML: Carcinoma of the colon. In: Colon and Rectal Surgery. Lippincott Williams \& Wilkins, Philadephia, p776, 2005.

4. Boland CR: Malignant tumors of the colon In: Textbook of Gastroenterology. Yamada T and Alpers DH (eds). Lippincott Williams \& Wilkins, Philadephia, p1952, 2003.

5. Hernández JL, Riancho JA, Matorras P and González-Macías J: Clinical evaluation for cancer in patients with involuntary weight loss without specific symptoms. Am J Med 114: 631-637, 2003.

6. Bosch X, Monclús E, Escoda O, Guerra-García M, Moreno P, Guasch N and López-Soto A: Unintentional weight loss: Clinical characteristics and outcomes in a prospective cohort of 2677 patients. PLoS One 12: e0175125, 2017.

7. Jemal A, Siegel R, Xu J and Ward E: Cancer statistics, 2010. CA Cancer J Clin 60: 277-300, 2011.

8. Weiss EG and Lavery I: Colon cancer evaluation and staging. In: The ASCRS Textbook of Colon and Rectal Surgery. Wolff BG and Fleshman JW (eds). Springer Science and Business Media LLC, New York, p385, 2007.

9. Kent AJ, Woolf D, McCue J and Greenfield SM: The use of symptoms to predict colorectal cancer site. Can we reduce the pressure on our endoscopy services? Colorectal Dis 12: 114-118, 2010.

10. Bloem RM, Zwaveling A and Stijnen T: Adenocarcinoma of the colon and rectum: A report on 624 cases. Neth J Surg 40: 121-126, 1988.

11. Alves A,Panis Y,Mantion G,SlimK,KwiatkowskiFand VicautE: The AFC score: Validation of a 4-item predicting score of postoperative mortality after colorectal resection for cancer or diverticulitis: Results of a prospective multicenter study in 1049 patients. Ann Surg 246: 91-96, 2007

12. Higgens CS, Keighley MR and Allan RN: Impact of preoperative weight loss and body composition changes on postoperative outcome in surgery for inflammatory bowel disease. Gut 25: 732-736, 1984.

13. Piessen G, Muscari F, Rivkine E, Sbaï-Idrissi MS, Lorimier G, Fingerhut A, Dziri C and Hay JM; FRENCH (Fédération de Recherche EN CHirurgie): Prevalence of and risk factors for morbidity after elective left colectomy: Cancer vs noncomplicated diverticular disease. Arch Surg 146: 1149-1155, 2011.

14. Burdy G, Panis Y, Alves A, Nemeth J, Lavergne-Slove A and Valleur P: Identifying patients with T3-T4 node-negative colon cancer at high risk of recurrence. Dis Colon Rectum 44: 1682-1688, 2001.

15. Diculescu M, Iacob R, Iacob S, Croitoru A, Becheanu G and Popeneciu V: The importance of histopathological and clinical variables in predicting the evolution of colon cancer. Rom J Gastroenterol 11: 183-189, 2002.

16. Andreyev HJ, Norman AR, Oates J and Cunningham D: Why do patients with weight loss have a worse outcome when undergoing chemotherapy for gastrointestinal malignancies? Eur J Cancer 34: 503-509, 1998.

17. Barber MD, Ross JA and Fearon KC: Disordered metabolic response with cancer and its management. World J Surg 24: 681-689, 2000

18. Choo MK, Sakurai H, Koizumi K and Saiki I: Stimulation of cultured colon 26 cells with TNF-alpha promotes lung metastasis through the extracellular signal-regulated kinase pathway. Cancer Lett 230: 47-56, 2005.

19. Ardizzoia A, Lissoni P, Brivio F, Tisi E, Perego MS, Grassi MG, Grassi MG, Pittalis S, Crispino S, Barni S and Tancini G: Tumor necrosis factor in solid tumors: Increased blood levels in the metastatic disease. J Biol Regul Homeost Agents 6: 103-107, 1992.

20. Knüpfer H and Preiss R: Serum interleukin-6 levels in colorectal cancer patients-a summary of published results. Int J Colorectal Dis 25: $135-140,2010$.

21. Daniel RE and Rule NO: Heavy matters: The relationship between just noticeable differences in perceptions of facial adiposity and facial attractiveness. Soc Psychol Pers Sci 7: 69-76, 2016.

22. Walpole SC, Prieto-Merino D, Edwards P, Cleland J, Stevens G and Roberts I: The weight of nations: An estimation of adult human biomass. BMC Public Health 12: 439, 2012. 